\section{Secondary Aneurysmal Bone Cyst of Base of Skull Associated with Chondroblastoma}

Sir,

Aneurysmal bone cysts (ABCs) are multi-cystic, osteolytic growths. The classic or standard form $(95 \%)$ has blood filled spaces among bony trabeculae. Osteoid tissue and osteoclastic giant cells are found in the stromal tissue. The solid form $(5 \%)$ shows fibroblastic proliferation, osteoid production and degenerated calcifying fibromyxoid elements. ${ }^{1} \mathrm{ABC}$ s are usually seen in younger patients. Around $80 \%$ of the patients are less than 20 years of age, more frequently in females. ABCs occurring de novo are called as primary $A B C s$. Secondary $A B C s$ have accompanying tumors like chondroblastoma and giant cell tumor in $30 \%$ of patients. Other associated tumors or non-tumorous conditions include ossifying fibroma, osteosarcoma, chondrosarcoma, non-ossifying fibroma, chondromyxoid fibroma, unicameral or solitary bone cyst or trauma. ${ }^{2}$

$A B C$ s are commonly found in long bones, membranous bones of the thorax, pelvis and vertebra. In long tubular bones, these tend to be eccentrically located in the metaphysis. However, these can occur in any location, including the diaphysis and epiphysis, rarely, involving multiple bones simultaneously. ${ }^{3}$ Skull is rarely affected. ${ }^{4,5}$

The treatment modalities include selective arterial embolization, irradiation, intralesional curettage, intraoperative adjuvants, bone grafting, marginal resection or wide excision. Tumor has to be excised and all cystic lining curetted. Cryotherapy, phenol or cauterizations (intraoperative adjuvants) are used to remove microscopic tumor cells. Resulting bony defects may be replaced with homologous bone or cadaveric bone.

We, herein, present a 50-year patient who was admitted with the complaints of headache, and rapidly enlarging swelling in the right temporal and mastoid area elevating the auricle. There was serosanguinous ear discharge and loss of hearing from right ear. There was no history of trauma. Swelling was non-tender, firm to hard and pulsatile. Cough impulse was negative and no bruit was audible. Right seventh nerve was paralysed with lower motor neuron features. No other body part was involved.

CT scan brain with contrast and CT-angio brain revealed a vascular mass with bony outgrowth and cystic spaces involving right temporal petrous and mastoid area with midline brain shift (Figure 1). Patient underwent operation and lesion was excised and surrounding bony area was cauterised. Attached dura was coagulated with bipolar diathermy. Histopathology report confirmed the diagnosis of chondroblastoma with secondary ABC. Patient remained well for one year, however, he had recurrence of same growth after one year. Second operation was performed in the same way. He was then referred for radiotherapy.

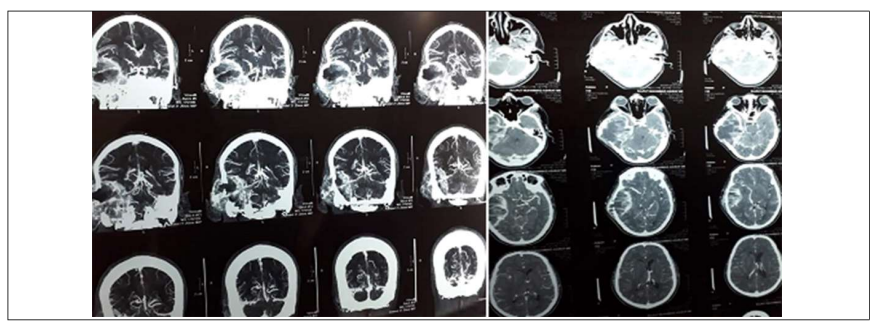

Figure 1: Contrast CT Brain axial and coronal sections showing vascular cystic lesion involving right temporal, petrous and mastoid bone with cavitations, elevation and thinning of outer table.

This case is unique as it presented at advanced age and in an unusual location. As mentioned above, skull is very rarely the primary site for this lesion. Both the primary tumour and the associated secondary $A B C$ are rare at this age. Moreover, this case recurred after one year. Recurrence is not rare in ABCs. Most commonly, it results from incomplete removal of the lesion. This patient underwent second surgery and was then referred to Radiotherapy Department to help prevent future recurrences.

This case highlights the need to keep this lesion in the differential diagnosis, whenever, imaging modalities show multi-cystic, osteolytic lesion in the skull bones.

\section{CONFLICT OF INTEREST:}

Authors declared no conflict of interest.

\section{AUTHORS' CONTRIBUTION:}

\section{SRB: Paper writing.}

MD: Literature search.

FAM: Photographs and proofreading.

\section{REFERENCES}

1. Saez N, Sharma GK, Barnes CH, Lu Y, Hsu FP, Huoh KC, et al. Solid variant of aneurysmal bone cyst of the temporal bone. Ann Otol Rhinol Laryngol 2018; 127:285-90.

2. Toescu SM, Alalade AF, Steele L, Bhargava D, Hunter R. Frontal skullosteoblastoma with aneurysmal bone cyst-like changes associated with trauma during pregnancy: A case report. Acta Neurochir (Wien) 2017; 159:393-6.

3. Kaloostian SW, Vartanian TK, Ordookhanian C, Vartanian T, Kaloostian PE. Concomittant fibrous dysplasia with aneurysmal bone cyst formation within the skull, humerus and rib. J Surg Case Rep 2018; 2018:rjy180.

4. Kim S, Jung DW, Pak MG, Song YJ, Bae WY. An aneurysmal bone cyst in the skull base. J Craniofac Surg 2017; 28:e704-6.

5. Ustabasioglu FE, Samanci C, Asik M, Yanik I, Ozkanli S, Tutar $\mathrm{O}$, et al. Aneurysmal bone cyst of sphenoid bone and clivus misdiagnosed as chordoma: A case report. Brain Tumor Res Treat 2015; 3:115-7.

Shams Raza Brohi, Muzamil Dilber and Fahmida Arab Mallah

Department of Neurosurgery, Peoples University of Medical and Health Sciences, Nawabshah, Pakistan

Correspondence to: Prof. Shams Raza Brohi, Department of

Neurosurgery, Peoples University of Medical and Health

Sciences, Shaheed Benazirabad, Nawabshah, Pakistan

E-mail: shamsbrohi@yahoo.com

Received: October 02, 2018; Revised: February 28, 2019;

Accepted: February 28, 2019 